\title{
Lifestyle and health-related quality of life: A cross-sectional study among civil servants in China
}

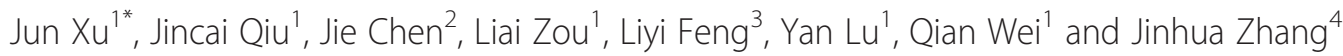

\begin{abstract}
Background: Health-related quality of life (HRQoL) has been increasingly acknowledged as a valid and appropriate indicator of public health and chronic morbidity. However, limited research was conducted among Chinese civil servants owing to the different lifestyle. The aim of the study was to evaluate the HRQoL among Chinese civil servants and to identify factors might be associated with their HRQOL.

Methods: A cross-sectional study was conducted to investigate HRQoL of 15,000 civil servants in China using stratified random sampling methods. Independent-Samples t-Test, one-way ANOVA, and multiple stepwise regression were used to analyse the influencing factors and the HRQOL of the civil servants.

Results: A univariate analysis showed that there were significant differences among physical component summary (PCS), mental component summary (MCS), and TS between lifestyle factors, such as smoking, drinking alcohol, having breakfast, sleep time, physical exercise, work time, operating computers, and sedentariness $(P<0.05)$. Multiple stepwise regressions showed that there were significant differences among TS between lifestyle factors, such as breakfast, sleep time, physical exercise, operating computers, sedentariness, work time, and drinking $(\mathrm{P}<0.05)$.

Conclusion: In this study, using Short Form 36 items (SF-36), we assessed the association of HRQoL with lifestyle factors, including smoking, drinking alcohol, having breakfast, sleep time, physical exercise, work time, operating computers, and sedentariness in China. The performance of the questionnaire in the large-scale survey is satisfactory and provides a large picture of the HRQoL status in Chinese civil servants. Our results indicate that lifestyle factors such as smoking, drinking alcohol, having breakfast, sleep time, physical exercise, work time, operating computers, and sedentariness affect the HRQoL of civil servants in China.
\end{abstract}

Keywords: Health-related quality of life, SF-36, Civil servants, Lifestyle

\section{Background}

The World Health Organization (WHO) defines quality of life as the living conditions associated with the corresponding goals, expectations, standards, and concerns of each individual living in different cultural systems [1-3]. The quality of life, as a new health indicator, is not only concerned about how long patients can survive, but more concerned about how well patients live. The first measurement of the quality of life is the United States national measurement report in 1960 by the United States Dwight D. Eisenhower National Goal Committee [4]. After the 1980s, the assessment of the quality of life

\footnotetext{
* Correspondence: drugstat@163.com

'Department of Sanitation Economy Administration, Nanfang Hospital, Southern Medical University, Guangzhou, Guangdong Province, PR China Full list of author information is available at the end of the article
}

in the allocation of health resources, the choice of patient (individual) treatments, the comparison of various treatments in clinical trials, and quality of life measurement in healthy people has been widely applied, and the WHO proposes the concept of health-related quality of life (HRQoL) [5]. The quality of life is mainly measured using rating scales, such as the Short Form 36 items (SF-36) scale [6]. The SF-36 scale has demonstrated reliability and validity in assessing the health of the general population, is a well-recognised outcome measure for health status, and has been used extensively as an important health outcome indicator [7]. With respect to the effects of factors on health, findings from previous studies among civil servants have shown how HRQoL is associated with disease, psychological problems, and so on [8-11]. However, very few studies 
examined whether and how HRQoL is associated with lifestyle and health among civil servants. This study is unique because the sample was nationally representative, and assessed the association between HRQoL and lifestyle factors, compared to differences between different lifestyle groups. Therefore, in this study we aimed to assess selfreported HRQoL among Chinese civil servants using the SF-36 instrument; the association between lifestyle factors and HRQoL, and the impact of lifestyle factors, such as smoking, drinking alcohol, having breakfast, sleep time, physical exercise, work time, operating computers, and sedentariness on HRQoL. Studying this issue can provide important information for local health care policy makers and researchers to consider at which levels effective public health interventions should be implemented to improve the HRQoL of civil servants and to further confirm the universal nature of association between lifestyle factors and health across cultural boundaries.

\section{Methods}

\section{Study population and data collection}

This was a cross-sectional survey of a random sample of civil servants selected from five regions (North China, South China, Central China, Northwest China, and Northeast China) in China. Civil servants in the present study refer to those who perform public duties and have been included in the state administrative system with wages and welfare provided by the state public finance [12]. The sampling method was based on a stratified random sampling approach. These five regions represent typical levels in respect of the regions scale and geographical distribution. North China, South China, and Central China are typical of greatly developed regions. Northeast China is representative of moderately developed regions. Northwest China is representative of underdeveloped regions. Overall, these five regions represent the characteristics of different types. Therefore, the survey of civil servants from these regions could well represent the HRQoL status of civil servants in China. Affiliation such as provincial, municipal, county, town, and village were randomly selected in five regions. All the participants had to be aged 18 years or older, including retired ones. Age was categorised into groups: 18-24 years, 25-34 years, 35-44 years, $45-54$ years, and 55 years or above. Proportionate allocation sampling was used to identify a sampling fraction for each district, age segment, and gender $($ male/female $=2 / 1)$. The sample sizes of each region, which can be calculated by formula [13], were 2,401. Taking the loss rate into account, we expand the sample size by adding $10 \%$. Considering the smallest sample size and different regions have different proportion of civil servants, the sample size of the civil servants living in North China, South China, Central China, Northwest China, and Northeast China were 4,050; 2,760; 2,580; 3,030; 2,580, respectively. A total of 15,000 civil servants in China were recruited in this study, and $93.47 \%(14,021)$ responded to the survey.

All the respondents gave written informed consent to all assessments reported and the study was approved by the Nanfang hospital ethics committee (see Additional file 1).

\section{Measurement tools}

A questionnaire survey was conducted. The questionnaire (see Additional file 2) involved two parts. The first part included general situations of Chinese civil servants. The second part was the HRQoL measurement scale: the SF-36.

General situations included socio-demographic factors, including gender, age, ethnic, height, weight, region, marital status, education, monthly income, and living place. Lifestyle included smoking, drinking alcohol, having breakfast, sleep time, physical exercise, work time, sedentariness, and life experience.

SF-36 is a form containing 36 items divided into eight dimensions of health using a multi-item scale [14]: physical functioning $(\mathrm{PF})$, role-physical (RP), bodily pain (BP), general health $(\mathrm{GH})$, vitality (VT), social functioning $(\mathrm{SF})$, role-emotional (RE), and mental health $(\mathrm{MH})$. The eight scales were scored from 0 to 100 (worst to best possible health status). The SF-36 is a reliable and validated instrument $[15,16]$. The physical health-related dimensions (physiological function, role-physical, bodily pain, general health) and mental health-related dimensions (vitality, social functions, role emotional, mental health) in SF-36 are assigned to physical component summary (PCS) and mental component summary (MCS) $[17,18]$. SF-36 was scored on the basis of national uniform standards in China. The score was then recalculated across the dimensions:

$$
\begin{aligned}
\text { transformed score }= & \frac{\text { Actual raw score }- \text { lowest possible raw score }}{\text { possible raw score range }} \\
& \times 100
\end{aligned}
$$

The raw score of each dimension was derived by summing the item scores, and then converted to a value ranging from 0 (worst possible health status measured by the questionnaire) to 100 (best possible health status) [19].

\section{Quality control}

The investigator explained to subjects how to fill in the scale before the test. Then, subjects fill the questionnaire independently on the basis of their understanding of each item. Afterwards, we rejected questionnaires that were less than $80 \%$ complete, had low writing quality (for instance, all of the questions were with the same answer), and those questionnaires that had identical answers. The database was established by Epidata3.02, and double input was conducted to ensure the lowest deviation. 


\section{Statistical analysis}

Epdata3.02 (Military Medical Science Press,Beijing, China) was adopted to manage the data in the survey. Statistical analysis was carried out using SPSS15.0 for Windows, version 15.0 (SPSS, Inc., Chicago, Illinois). The statistical description of the clinical and socio-demographic variables was denoted by frequencies, percentages, means, and standard deviations. After calculating descriptive statistics, t-tests and a one-way ANOVA were used to assess group differences with respect to their statistical significance. Additionally, multivariate stepwise regression analysis was performed to assess the impact of gender, educational level, and living arrangements on HRQoL.

\section{Results}

\section{Demographic characteristics of the participants}

Totally, 15,000 participants received the interview and 14,021 (93.47\%) responded to the survey. Among them, $12,941(92.30 \%)$ were included in the data analyses. As shown in Table 1, 7,953 (61.46\%) were males and 4,904 (37.90\%) were females. The percentages of the civil servants in North China, South China, Central China, Northwest China, and Northeast China were 3,610 (27.90\%); 2,492 (19.26\%); 1,973 (15.25\%); 2,695 (20.83\%); $2,171(16.78 \%)$, respectively. The means (SD) age of the participants was 38.72 (9.43).

\section{HRQoL of Chinese civil servants}

Table 2 shows the scores of HRQoL among Chinese civil servants.

\section{Univariate analysis}

Table 3 and 4 shows the relationships between the lifestyle factors and HRQoL.

Significant differences among PCS, MCS, and TS between lifestyle factors were found $(P<0.05)$. The smoking group had lower scores in PCS, MCS, and TS than the non-smoking group; civil servants who drank a little had higher scores in PCS, MCS, and TS than civil servants who never drank or drank a lot. The scores of the servants who never ate breakfast were significantly lower than those of other groups. The group in which civil servants had 8-10 hours sleep had higher scores in PCS, MCS, and TS than other groups. The group in which civil servants had 4 hours or less sleep had the lowest scores. Civil servants who participated in physical exercise more than 12 times a month had higher scores in PCS, MCS, and TS. Civil servants who had little or no physical exercise had the lowest scores. Civil servants who worked less than 10 hours a day had higher scores in PCS, MCS, and TS than those who worked more than 10 hours a day. Civil servants always operating computers and who were mostly sedentary had lower scores in PCS, MCS, and TS than those in other groups.

\section{Multiple stepwise linear regressions analysis}

The SF-36 scale total score was used as the dependent variable, and lifestyle factors, as independent variables. Multiple linear regression was conducted to analyse the social-demographic factors that affect Chinese civil servants' HRQoL. The regression results showed that there were significant differences among PCS, MCS, and TS between lifestyle factors, such as sleep time, having breakfast, physical exercise, operating computers, sedentariness, drinking alcohol, and smoking in PCS; having breakfast, sleep time, physical exercise, operating computers, sedentariness, and work time in MCS; having breakfast, sleep time, physical exercise, operating computers, sedentariness, work time, and drinking alcohol in TS $(\mathrm{P}<0.05)$ (see Table 5).

\section{Discussion}

This study has shown that Chinese civil servants who are frequently under excessive pressure of work, interpersonal relationships, and family stress may have physical and mental disorders, serious psychological fatigue, and psychological problems. The physical and mental disorders may in turn increase the pressure and lead to subhealth and various diseases $[20,21]$, and may eventually reduce the efficiency of work and decrease HRQoL.

Personal habits will have an impact on the HRQoL of Chinese civil servants. This research shows that lifestyle factors such as smoking, drinking alcohol, having breakfast, sleep time, physical exercise, work time, operating computers, and sedentariness have a strong association with civil servants' HRQoL.

Bad living habits such as smoking and drinking are major factors causing the decline of physical condition $[22,23]$. Previous studies have shown that under the influence of alcohol, drinking a little can make blood vessels expand and relax. Alcohol goes into the blood circulation and has a certain inhibition on the sympathetic system. Therefore, moderate drinking may protect the cardiovascular and cerebrovascular system [24,25]. As the result showed, civil servants who drank a little had higher HRQoL than civil servants who never drank or drank a lot. That means moderate drinking has benefits on civil servants' quality of life. In this study, the total drinking rate among civil servants is $62.52 \%$. There may be two reasons; first, they participate in some social drinking or alcoholism because of friendly gatherings, work entertainment, personal appetite, and many other reasons. Second, in order to pursue self-health, they have a small amount of alcohol safely at home under the influence of the concept that moderate alcohol consumption has a protective effect on the cardiovascular system. For civil servants, risks of social drinking or alcoholism are enormous. A good grasp of the safety of self-protective drinking is difficult, and a little excessive drinking not only has no benefits but is 
Table 1 Frequency distribution of civil servants' demographical and lifestyle characteristics $(N=12941)$

\begin{tabular}{|c|c|c|c|c|c|c|c|}
\hline Factors & Groups & $\mathrm{N}$ & $\%$ & Factors & Groups & $\mathrm{N}$ & $\%$ \\
\hline \multirow[t]{3}{*}{ Gender } & Male & 7953 & 61.46 & Breakfast & Never & 249 & 1.92 \\
\hline & Female & 4904 & 37.90 & & Sometimes & 1386 & 10.71 \\
\hline & Missing value & 84 & 0.65 & & Often & 4355 & 33.65 \\
\hline \multirow[t]{6}{*}{ Age } & $18 \sim$ & 459 & 3.55 & & Every day & 6860 & 53.01 \\
\hline & 25 & 4209 & 32.52 & & Missing value & 91 & 0.70 \\
\hline & 35 & 4377 & 33.82 & Sleeping time & Below 4 & 110 & 0.85 \\
\hline & 45 & 3094 & 23.91 & & 4 & 448 & 3.46 \\
\hline & 55 & 692 & 5.35 & & $6 \sim$ & 6251 & 48.30 \\
\hline & Missing value & 110 & 0.85 & & 8 & 5925 & 45.78 \\
\hline \multirow[t]{5}{*}{ Region } & North China & 3610 & 27.90 & & $10 \sim$ & 132 & 1.02 \\
\hline & South China, & 2492 & 19.26 & & Missing value & 75 & 0.58 \\
\hline & Central China & 1973 & 15.25 & Physical exercise $^{\text {a }}$ & Little or not & 4683 & 36.19 \\
\hline & Northwest China & 2695 & 20.83 & & $1 \sim 4$ & 1939 & 14.98 \\
\hline & Northeast China & 2171 & 16.78 & & $5 \sim 8$ & 3793 & 29.31 \\
\hline \multirow[t]{4}{*}{ Marital status } & Non-married & 1845 & 14.26 & & $9 \sim 12$ & 1050 & 8.11 \\
\hline & Married & 10619 & 82.06 & & Above 12 & 1345 & 10.39 \\
\hline & Divorced/Widowed/Other & 331 & 2.56 & & Missing value & 131 & 1.01 \\
\hline & Missing value & 146 & 1.13 & Work time & Below 6 & 1425 & 11.01 \\
\hline \multirow[t]{5}{*}{ Education } & Middle school & 105 & 0.81 & & 6 & 9506 & 73.46 \\
\hline & High school & 685 & 5.29 & & $10 \sim$ & 1273 & 9.84 \\
\hline & College & 11183 & 86.42 & & $12 \sim$ & 386 & 2.98 \\
\hline & Under graduate & 738 & 5.70 & & Missing value & 351 & 2.71 \\
\hline & Missing value & 230 & 1.78 & Sedentariness ${ }^{b}$ & Rarely & 5293 & 40.90 \\
\hline \multirow[t]{3}{*}{ Smoke } & No & 9082 & 70.18 & & Sometimes & 2814 & 21.74 \\
\hline & Yes & 3807 & 29.42 & & Often & 2841 & 21.95 \\
\hline & Missing value & 52 & 0.40 & & Always & 1913 & 14.78 \\
\hline \multirow[t]{4}{*}{ Drink } & Never & 2990 & 23.10 & & Missing value & 80 & 0.62 \\
\hline & A little & 7034 & 54.35 & & & & \\
\hline & A lot & 2782 & 21.50 & & & & \\
\hline & Missing value & 135 & 1.04 & & & & \\
\hline
\end{tabular}

a: Little or not, $1 \sim 4$ times a month, 5 8 times a month, 9 12 times a month, Above 12 times a month.

b: Operating computer and sedentariness.

extremely harmful to health. Therefore, government departments should pay enough attention to this problem. In the study, the total smoking rate among civil servants is $34.27 \%$. Smoking is a great threat to human life, and induces death by cardiovascular disease of $11 \%$ of the total population in the world [22]. A Norwegian study shows that smokers who smoke 1-4 cigarettes a day have more risk of ischemic heart disease than non-smokers [26]. At the same time, the dangers of passive smoking on the human body cannot be ignored. Global researches on passive smoking and lung cancer indicate that there is a causal association between the occurrence of lung cancer and passive smoking [27]. Therefore, smoking can physically cause harm to civil servants. The more smoking, the greater damage there is to civil servants' physical health and lower PCS scores.

Decline in HRQoL is closely related to poor eating habits and irregular lifestyle. For civil servants, poor diet includes too simple a breakfast or having no breakfast. The body in a state of hunger may easily lead to palpitation, dizziness, mental deficiencies, and so on. In the study, some civil servants had no breakfast or rarely did so, and the proportion of those having breakfast daily was $61.68 \%$. We may see that the phenomenon of irregular diet and no breakfast among civil servants is serious. As a basic human need, food intake affects people's HRQoL [28]. Scientific diet is the healthy material guarantee. Civil servants should change bad eating 
Table 2 HRQoL of Chinese civil servants $(\mathrm{N}=12941)$

\begin{tabular}{llcc}
\hline Scale & & Means & SD \\
\hline $\begin{array}{l}\text { Physical health } \\
\text { scales(PCS) }\end{array}$ & & 76.05 & 14.71 \\
& Physical Functioning (PF) & 88.50 & 15.58 \\
& Role Physical (RP) & 79.24 & 32.64 \\
& Bodily Pain (BP) & 75.95 & 19.56 \\
& Mental Health (MH) & 63.00 & 19.51 \\
& & 72.01 & 15.89 \\
Mental health & & & \\
scales(MCS) & & 68.83 & 17.39 \\
& Role Emotional (RE) & 78.62 & 19.36 \\
& Social Functioning (SF) & 74.39 & 37.29 \\
& Vitality (VT) & 72.15 & 17.10 \\
& General Health (GH) & 73.99 & 14.15 \\
\hline & & & \\
\hline
\end{tabular}

habits, have food on time, and pay attention to a reasonable nutrition.

Sleep time is closely related to HRQoL [29]. As a physiological activity, sleep is more important than eating, and all the body's vital functions are slowed down, completely at the state of rest, recovering and accumulating energy. If one has prolonged insomnia, this will lead inevitably to the irreparability of energy and spirit, and life exhaustion. A British and American study has shown that sleeping less than 6 hours per day is linked to the occurrence of some diseases, and people sleeping more than 8 hours per day show only minor illness with epiphenomenon [23]. As an important physiological process, sleeping not only maintains normal function but also protects the normal metabolism and functions of various organs of body. If one cannot get adequate sleep, many negative manifestations such as sleep deprivation, physical fatigue discomfort, and other negative emotions with tension and anxiety may occur, therefore, leading to a decline in reactions, enthusiasm, abilities in solving problems, and HRQoL. As the previous studies showed above, sleeping problems may lead to poor sleep quality and illness, which might decline HRQoL. This might explain why civil servants who had 8-10 hours sleep had higher scores in PCS, MCS, and TS. In addition, adequate sleep is quite important, which can reduce and relieve stress for mental and emotional balance. Therefore, civil servants should arrange work and study reasonably to ensure adequate sleep.

Physical exercise can reduce the risk of many diseases, such as ischemic heart disease [30], stroke [31], diabetes [32], cognitive disorder [12], and total mortality [33]. And moderate exercise can promote physical and mental health of individuals. Physical exercise can not only improve adaptability of cardiopneumatic and disease resistance, reduce diseases, enhance the body, and avoid obesity, but it can also help maintain a strong energy to improve efficiency at work. Appropriate exercise is conducive to physical and mental health, which can make people relax, eliminate tension, and enhance the immunity and adaptability to the environment. Taking part in various sports activities can improve HRQoL, by exercising, improving community participation, and so on. The study found that $32.58 \%$ of civil servants have scarcely done physical exercise. Heavy tasks, personal stress, body fatigue after work, having no interest in sports, and lack of sports site, equipment, and facilities may be the reasons that affect civil servants' initiative and level of participating in exercise.

This study indicated that work time is associated with HRQoL. Long-term working and work entertainment increase civil servants' workload directly, reduce their leisure time, and potentially add to their work pressure, which may gradually make satisfaction and enthusiasm for their job weaken with lack of energy. What is more, they result in boredom, anxiety, depression, and other psychological symptoms, and affect individual health and induce the decline of life quality. A five-year follow-up survey of UK White House showed that the danger of civil servants working more than 55 hours per week and suffering from depression or anxiety symptoms is 1.66 times and 1.74 times respectively than civil servants working 35-40 hours per week, and long-term working is excessively dangerous for women civil servants[34]. Many factors such as a long period of overtime, excessive work, and mental stress also affect the health of employees indirectly [35,36]. Therefore, civil servants who worked less than 10 hours a day had higher scores in PCS, MCS, and TS than those who worked more than 10 hours a day.

Operating computers and sedentariness have an adverse effect on health [37]. Civil servants' characteristics were 'entertainment-style,' 'stay-up-late-style,' 'sitting silently type', 'meeting-style', and 'thinking-style'. Among these characteristics, 'stay-up-late-style, 'sitting silently type, 'meetingstyle', and 'thinking-style' usually need long-term operating of computers, which induces a variety of chronic diseases, such as cervical spondylosis, scapulohumeral periarthritis, obesity, fatty liver, hypertension, and hyperlipoidemia. And these diseases have a negative impact on the health of civil servants, followed by the deterioration of health quality and the gradual descent of work efficiency.

\section{Limitation}

In this study, the performance of the questionnaire in a large-scale survey is satisfactory and provides a large picture of the HRQoL of civil servants in China. However, several limitations need to be taken into account when interpreting our findings. Firstly, our use of data from five regions (North China, South China, Central China, Northwest China, and Northeast China) in China limited the 
Table 3 HRQoL associated with lifestyle factors in physiological among Chinese civil servants $(N=12941)$

\begin{tabular}{|c|c|c|c|c|c|c|}
\hline \multirow[t]{2}{*}{ Factors } & \multirow[t]{2}{*}{ Groups } & \multicolumn{5}{|c|}{ Physical health scales (PCS) } \\
\hline & & $\mathrm{PF}$ & $\mathrm{RP}$ & BP & GH & PCS summary measure \\
\hline \multirow[t]{4}{*}{ Smoke } & No & $89.04 \pm 14.86$ & $80.44 \pm 32.03$ & $76.03 \pm 19.32$ & $63.43 \pm 19.34$ & $50.83 \pm 8.24$ \\
\hline & Yes & $87.23 \pm 17.10$ & $76.47 \pm 33.82$ & $75.67 \pm 20.11$ & $61.97 \pm 19.87$ & $50.00 \pm 9.00$ \\
\hline & $\mathbf{t}$ & 5.698 & 6.173 & 0.930 & 3.868 & 4.906 \\
\hline & $\mathbf{P}$ & 0.000 & 0.000 & 0.352 & 0.000 & 0.000 \\
\hline \multirow[t]{5}{*}{ Drink } & Never & $86.54 \pm 17.93$ & $79.16 \pm 32.37$ & $75.34 \pm 20.95$ & $63.05 \pm 19.63$ & $49.95 \pm 9.17$ \\
\hline & A little & $89.41 \pm 14.35$ & $79.96 \pm 32.22$ & $76.12 \pm 18.91$ & $63.16 \pm 19.57$ & $50.87 \pm 8.09$ \\
\hline & A lot & $88.68 \pm 15.45$ & $78.29 \pm 33.46$ & $76.30 \pm 19.65$ & $62.97 \pm 19.05$ & $50.76 \pm 8.59$ \\
\hline & $\mathbf{F}$ & 35.901 & 2.733 & 2.145 & 0.102 & 12.723 \\
\hline & $\mathbf{P}$ & 0.000 & 0.065 & 0.117 & 0.903 & 0.000 \\
\hline \multirow[t]{6}{*}{ Breakfast } & Never & $73.72 \pm 25.60$ & $65.61 \pm 35.75$ & $62.23 \pm 25.23$ & $56.65 \pm 17.10$ & $44.49 \pm 11.13$ \\
\hline & Sometimes & $83.30 \pm 20.17$ & $70.39 \pm 36.07$ & $70.21 \pm 20.68$ & $58.19 \pm 19.41$ & $48.00 \pm 10.00$ \\
\hline & Often & $88.20 \pm 15.73$ & $77.72 \pm 33.12$ & $75.77 \pm 19.14$ & $61.82 \pm 18.89$ & $50.47 \pm 8.36$ \\
\hline & Every day & $90.36 \pm 13.12$ & $82.60 \pm 30.84$ & $77.75 \pm 18.94$ & $65.00 \pm 19.71$ & $51.44 \pm 7.89$ \\
\hline & $\mathbf{F}$ & 166.341 & 77.321 & 102.348 & 67.226 & 112.097 \\
\hline & $\mathbf{P}$ & 0.000 & 0.000 & 0.000 & 0.000 & 0.000 \\
\hline \multirow[t]{7}{*}{ Sleeping time } & Below 4 & $74.08 \pm 28.35$ & $66.45 \pm 34.58$ & $62.37 \pm 25.75$ & $54.99 \pm 19.51$ & $44.30 \pm 12.22$ \\
\hline & $4 \sim$ & $74.39 \pm 25.72$ & $65.03 \pm 36.20$ & $62.47 \pm 21.23$ & $53.04 \pm 19.16$ & $43.75 \pm 11.35$ \\
\hline & $6 \sim$ & $87.99 \pm 15.26$ & $77.69 \pm 33.44$ & $74.30 \pm 19.56$ & $60.98 \pm 19.63$ & $50.05 \pm 8.59$ \\
\hline & $8 \sim$ & $90.52 \pm 13.50$ & $82.31 \pm 30.93$ & $78.96 \pm 18.46$ & $65.99 \pm 18.81$ & $51.83 \pm 7.57$ \\
\hline & $10 \sim$ & $83.83 \pm 20.41$ & $74.85 \pm 35.19$ & $76.60 \pm 21.43$ & $64.43 \pm 20.91$ & $49.20 \pm 10.58$ \\
\hline & $\mathbf{F}$ & 152.062 & 43.233 & 116.845 & 87.831 & 131.978 \\
\hline & $\mathbf{P}$ & 0.000 & 0.000 & 0.000 & 0.000 & 0.000 \\
\hline \multirow[t]{7}{*}{ Physical exercise } & Little or not & $87.56 \pm 15.70$ & $78.15 \pm 34.09$ & $74.67 \pm 19.82$ & $59.90 \pm 20.05$ & $49.79 \pm 8.58$ \\
\hline & $1 \sim 4$ & $87.32 \pm 16.86$ & $76.55 \pm 33.69$ & $74.51 \pm 19.96$ & $63.89 \pm 18.53$ & $50.15 \pm 8.74$ \\
\hline & $5 \sim 8$ & $88.94 \pm 15.70$ & $79.51 \pm 31.61$ & $76.37 \pm 18.62$ & $63.15 \pm 18.74$ & $50.86 \pm 8.25$ \\
\hline & $9 \sim 12$ & $90.58 \pm 14.08$ & $81.18 \pm 31.02$ & $78.37 \pm 20.61$ & $67.04 \pm 19.00$ & $52.22 \pm 8.55$ \\
\hline & Above 12 & $91.08 \pm 12.91$ & $84.67 \pm 29.26$ & $79.64 \pm 18.96$ & $69.10 \pm 19.59$ & $52.13 \pm 7.94$ \\
\hline & $\mathbf{F}$ & 21.996 & 14.945 & 24.271 & 76.231 & 33.571 \\
\hline & $\mathbf{P}$ & 0.000 & 0.000 & 0.000 & 0.000 & 0.000 \\
\hline \multirow[t]{6}{*}{ Work time } & Below 6 & $86.70 \pm 17.38$ & $79.26 \pm 32.63$ & $73.87 \pm 20.23$ & $62.42 \pm 19.32$ & $49.60 \pm 9.17$ \\
\hline & $6 \sim$ & $89.07 \pm 14.76$ & $80.64 \pm 31.62$ & $76.77 \pm 18.98$ & $63.95 \pm 19.15$ & $50.92 \pm 8.08$ \\
\hline & $10 \sim$ & $87.55 \pm 16.78$ & $70.66 \pm 36.86$ & $72.84 \pm 20.57$ & $58.41 \pm 20.70$ & $49.49 \pm 9.04$ \\
\hline & $12 \sim$ & $85.98 \pm 19.70$ & $73.05 \pm 36.67$ & $72.99 \pm 24.17$ & $59.76 \pm 23.09$ & $50.35 \pm 11.67$ \\
\hline & $\mathbf{F}$ & 15.757 & 40.167 & 24.808 & 35.051 & 18.675 \\
\hline & $\mathbf{P}$ & 0.000 & 0.000 & 0.000 & 0.000 & 0.000 \\
\hline \multirow[t]{6}{*}{ Sedentariness } & Rarely & $90.09 \pm 13.30$ & $80.90 \pm 31.75$ & $77.12 \pm 18.26$ & $64.07 \pm 19.18$ & $51.19 \pm 7.70$ \\
\hline & Sometimes & $88.11 \pm 15.84$ & $79.07 \pm 32.57$ & $77.69 \pm 19.66$ & $64.33 \pm 18.74$ & $50.82 \pm 8.41$ \\
\hline & Often & $90.03 \pm 13.36$ & $79.89 \pm 32.96$ & $74.22 \pm 19.90$ & $60.12 \pm 20.68$ & $50.66 \pm 8.49$ \\
\hline & Always & $82.70 \pm 21.41$ & $74.55 \pm 33.91$ & $72.83 \pm 21.76$ & $62.59 \pm 19.36$ & $48.63 \pm 10.18$ \\
\hline & $\mathbf{F}$ & 120.206 & 18.195 & 37.654 & 30.707 & 44.334 \\
\hline & $\mathbf{P}$ & 0.000 & 0.000 & 0.000 & 0.000 & 0.000 \\
\hline
\end{tabular}


Table 4 HRQoL associated with lifestyle factors in psychological among civil servants $(N=12941)$

\begin{tabular}{|c|c|c|c|c|c|c|}
\hline \multirow[t]{2}{*}{ Factors } & \multirow[t]{2}{*}{ Groups } & \multicolumn{5}{|c|}{ Mental health scales (MCS) } \\
\hline & & VT & SF & $\mathrm{RE}$ & MH & MCS summary measure \\
\hline \multirow[t]{4}{*}{ Smoke } & No & $69.31 \pm 17.22$ & $79.30 \pm 19.01$ & $75.10 \pm 37.00$ & $72.69 \pm 16.80$ & $50.86 \pm 9.31$ \\
\hline & Yes & $67.64 \pm 17.74$ & $77.00 \pm 20.07$ & $72.67 \pm 37.92$ & $70.86 \pm 17.74$ & $49.98 \pm 9.67$ \\
\hline & $\mathbf{t}$ & 4.910 & 6.022 & 3.342 & 5.431 & 4.816 \\
\hline & $\mathbf{P}$ & 0.000 & 0.000 & 0.001 & 0.000 & 0.000 \\
\hline \multirow[t]{5}{*}{ Drink } & Never & $68.62 \pm 17.64$ & $77.38 \pm 20.56$ & $76.58 \pm 35.52$ & $71.20 \pm 17.72$ & $50.72 \pm 9.21$ \\
\hline & A little & $69.02 \pm 17.33$ & $79.62 \pm 18.80$ & $75.07 \pm 36.72$ & $72.66 \pm 16.75$ & $50.82 \pm 9.40$ \\
\hline & A lot & $68.83 \pm 17.20$ & $77.86 \pm 19.14$ & $71.05 \pm 39.67$ & $72.17 \pm 17.18$ & $50.12 \pm 9.62$ \\
\hline & $\mathbf{F}$ & 0.591 & 17.712 & 17.570 & 7.694 & 5.700 \\
\hline & $\mathbf{P}$ & 0.554 & 0.000 & 0.000 & 0.000 & 0.003 \\
\hline \multirow[t]{6}{*}{ Breakfast } & Never & $58.90 \pm 17.20$ & $62.34 \pm 23.04$ & $61.74 \pm 39.12$ & $56.62 \pm 16.81$ & $44.64 \pm 9.29$ \\
\hline & Sometimes & $62.52 \pm 17.75$ & $70.68 \pm 21.90$ & $64.52 \pm 39.45$ & $64.91 \pm 17.30$ & $46.91 \pm 9.37$ \\
\hline & Often & $67.54 \pm 17.44$ & $77.02 \pm 19.11$ & $72.10 \pm 38.17$ & $70.55 \pm 17.02$ & $49.61 \pm 9.36$ \\
\hline & Every day & $71.29 \pm 16.75$ & 81.9017 .84 & $78.34 \pm 35.54$ & $75.25 \pm 16.20$ & $52.21 \pm 9.10$ \\
\hline & $\mathbf{F}$ & 146.219 & 223.547 & 74.366 & 253.684 & 195.408 \\
\hline & $\mathbf{P}$ & 0.000 & 0.000 & 0.000 & 0.000 & 0.000 \\
\hline \multirow[t]{7}{*}{ Sleeping time } & Below 4 & $60.85 \pm 16.70$ & $63.08 \pm 24.15$ & $58.64 \pm 38.82$ & $59.56 \pm 18.22$ & $45.41 \pm 8.87$ \\
\hline & 4 & $58.37 \pm 19.21$ & $62.44 \pm 23.97$ & $62.35 \pm 38.75$ & $59.74 \pm 18.14$ & $45.47 \pm 9.61$ \\
\hline & 6 & $67.06 \pm 17.45$ & $77.71 \pm 19.46$ & $71.32 \pm 38.80$ & $70.87 \pm 17.15$ & $49.76 \pm 9.67$ \\
\hline & 8 & $71.57 \pm 16.59$ & $81.10 \pm 17.88$ & $78.92 \pm 34.79$ & $74.68 \pm 16.23$ & $51.96 \pm 8.87$ \\
\hline & $10 \sim$ & $69.53 \pm 17.74$ & $80.14 \pm 19.46$ & $72.59 \pm 38.65$ & $72.06 \pm 18.32$ & $51.51 \pm 9.34$ \\
\hline & $\mathbf{F}$ & 102.465 & 128.853 & 49.876 & 119.371 & 87.382 \\
\hline & $\mathbf{P}$ & 0.000 & 0.000 & 0.000 & 0.000 & 0.000 \\
\hline \multirow[t]{7}{*}{ Physical exercise } & Little or not & $66.31 \pm 18.65$ & $77.99 \pm 19.80$ & $73.25 \pm 38.46$ & $70.84 \pm 17.68$ & $49.95 \pm 9.91$ \\
\hline & $1 \sim 4$ & $68.59 \pm 16.46$ & $76.18 \pm 19.49$ & $72.13 \pm 37.32$ & $70.73 \pm 17.31$ & $49.92 \pm 9.07$ \\
\hline & $5 \sim 8$ & $69.15 \pm 16.26$ & $78.78 \pm 18.79$ & $74.51 \pm 36.65$ & $71.89 \pm 16.38$ & $50.51 \pm 9.04$ \\
\hline & $9 \sim 12$ & $71.42 \pm 15.65$ & $78.53 \pm 19.45$ & $73.28 \pm 38.12$ & $73.46 \pm 16.56$ & $50.65 \pm 9.11$ \\
\hline & Above 12 & $75.00 \pm 16.60$ & $84.14 \pm 17.90$ & $81.73 \pm 33.48$ & $78.71 \pm 15.38$ & $54.08 \pm 8.70$ \\
\hline & $\mathbf{F}$ & 74.817 & 36.820 & 16.184 & 62.813 & 55.101 \\
\hline & $\mathbf{P}$ & 0.000 & 0.000 & 0.000 & 0.000 & 0.000 \\
\hline \multirow[t]{6}{*}{ Work time } & Below 6 & $69.47 \pm 16.48$ & $78.38 \pm 19.93$ & $73.83 \pm 36.55$ & $73.00 \pm 16.48$ & $51.22 \pm 8.99$ \\
\hline & $6 \sim$ & $69.92 \pm 16.74$ & $79.47 \pm 18.74$ & $76.78 \pm 35.73$ & $73.11 \pm 16.62$ & $51.23 \pm 9.11$ \\
\hline & $10 \sim$ & $62.35 \pm 20.10$ & $74.01 \pm 21.61$ & $63.96 \pm 42.45$ & $66.51 \pm 19.18$ & $46.95 \pm 10.75$ \\
\hline & $12 \sim$ & $60.64 \pm 19.93$ & $72.39 \pm 21.66$ & $48.79 \pm 45.08$ & $65.68 \pm 18.65$ & $44.66 \pm 10.08$ \\
\hline & $\mathbf{F}$ & 103.041 & 43.833 & 109.333 & 77.222 & 134.325 \\
\hline & $\mathbf{P}$ & 0.000 & 0.000 & 0.000 & 0.000 & 0.000 \\
\hline \multirow[t]{6}{*}{ Sedentariness } & Rarely & $70.09 \pm 16.76$ & $80.76 \pm 17.70$ & $76.31 \pm 36.73$ & $74.17 \pm 16.43$ & $51.50 \pm 9.22$ \\
\hline & Sometimes & $70.49 \pm 16.68$ & $78.41 \pm 19.67$ & $75.98 \pm 35.77$ & $72.50 \pm 16.92$ & $51.05 \pm 9.10$ \\
\hline & Often & $66.68 \pm 18.64$ & $79.27 \pm 19.15$ & $71.30 \pm 39.54$ & $71.33 \pm 17.01$ & $49.67 \pm 10.03$ \\
\hline & Always & $66.26 \pm 17.51$ & $72.26 \pm 22.05$ & $71.73 \pm 36.86$ & $67.44 \pm 18.21$ & $48.95 \pm 9.16$ \\
\hline & $\mathbf{F}$ & 46.897 & 93.495 & 16.207 & 76.918 & 47.384 \\
\hline & $\mathbf{P}$ & 0.000 & 0.000 & 0.000 & 0.000 & 0.000 \\
\hline
\end{tabular}


Table 5 Relationships between the lifestyle factors and HRQoL (Multivariate analysis $N=12941$ )

\begin{tabular}{|c|c|c|c|c|c|c|c|}
\hline \multirow{2}{*}{$\begin{array}{l}\text { Scales } \\
\text { PCS }\end{array}$} & \multirow[t]{2}{*}{ B } & \multirow[t]{2}{*}{ SE } & \multirow[t]{2}{*}{$\beta$} & \multirow[t]{2}{*}{$\mathbf{t}$} & \multirow[t]{2}{*}{$\mathbf{P}$} & \multicolumn{2}{|c|}{$95 \% \mathrm{Cl}$} \\
\hline & & & & & & & \\
\hline Sleeping time & 3.743 & 0.210 & 0.159 & 17.830 & 0.000 & 3.332 & 4.155 \\
\hline Breakfast & 2.491 & 0.177 & 0.127 & 14.041 & 0.000 & 2.143 & 2.839 \\
\hline Physical exercise & 1.200 & 0.097 & 0.109 & 12.416 & 0.000 & 1.011 & 1.390 \\
\hline Operating computer and sedentariness & -0.765 & 0.083 & -0.080 & -9.186 & 0.000 & -0.929 & -0.602 \\
\hline Drink & 0.691 & 0.208 & 0.032 & 3.314 & 0.001 & 0.282 & 1.099 \\
\hline Smoke & -0.682 & 0.309 & -0.021 & -2.209 & 0.027 & -1.287 & -0.077 \\
\hline \multicolumn{8}{|l|}{ MCS } \\
\hline Breakfast & 3.842 & 0.188 & 0.181 & 20.428 & 0.000 & 3.473 & 4.211 \\
\hline Sleeping time & 3.565 & 0.224 & 0.140 & 15.934 & 0.000 & 3.126 & 4.003 \\
\hline Physical exercise & 1.271 & 0.103 & 0.107 & 12.335 & 0.000 & 1.069 & 1.473 \\
\hline Operating computer and sedentariness & -1.046 & 0.089 & -0.101 & -11.788 & 0.000 & -1.220 & -0.872 \\
\hline Work time & -1.628 & 0.166 & -0.084 & -9.792 & 0.000 & -1.954 & -1.302 \\
\hline \multicolumn{8}{|l|}{ TS } \\
\hline Breakfast & 3.195 & 0.167 & 0.169 & 19.125 & 0.000 & 2.868 & 3.523 \\
\hline Sleeping time & 3.675 & 0.199 & 0.162 & 18.457 & 0.000 & 3.285 & 4.066 \\
\hline Physical exercise & 1.228 & 0.092 & 0.116 & 13.392 & 0.000 & 1.048 & 1.408 \\
\hline Operating computer and sedentariness & -0.909 & 0.079 & -0.099 & -11.522 & 0.000 & -1.064 & -0.755 \\
\hline Work time & -0.954 & 0.148 & -0.055 & -6.440 & 0.000 & -1.245 & -0.664 \\
\hline Drink & 0.426 & 0.181 & 0.020 & 2.348 & 0.019 & 0.070 & 0.782 \\
\hline
\end{tabular}

Statistical methods: multiple stepwise linear regression analysis.

applicability of our result to other countries. Secondly, the study design was cross-sectional and it is hence difficult to establish a cause-effect relationship between HRQoL and lifestyle factors. A longitudinal study is needed to investigate the relationship in a future study. Despite these limitations, the results of this analysis provide a large picture of the HRQoL of civil servants in China, which may facilitate further investigation by using a prospective study design.

\section{Conclusions}

In this study, using SF-36, we assessed the association of HRQoL with lifestyle factors, including smoking, drinking alcohol, having breakfast, sleep time, physical exercise, work time, operating computers, and sedentariness in China. The performance of the questionnaire in the large-scale survey is satisfactory and provides a large picture of HRQoL status in Chinese civil servants. The study showed that lifestyle factors such as smoking, drinking alcohol, having breakfast, sleep time, physical exercise, work time, operating computers, and sedentariness affect the HRQoL of Chinese civil servants. Multiple stepwise regressions showed that lifestyle factors such as smoking, drinking, breakfast, sleep time, physical exercise, work time, operating computers, and sedentariness affect the HRQoL of Chinese civil servants.

\section{Additional files}

Additional file 1: Ethical approval.

Additional file 2: Questionnaire.

\section{Abbreviations}

HRQOL: Health-related quality of life; SF-36: Short form 36 items; One-Way ANOVA: One-Way Analysis of Variance; PCS: Physical Component Summary of the SF-36; MCS: Mental Component Summary of the SF-36; TS: Total Scores of the SF-36; PF: Physical Functioning; RP: Role-Physical; BP: Bodily Pain; GH: General Health; VT: Vitality; SF: Social Functioning; RE: Role-Emotional; $\mathrm{MH}$ : Mental Health.

\section{Competing interests}

The authors declare that they have no competing interests.

\section{Acknowledgements}

We thank all the participants in this study. The authors are indebted to the supervisors in five regions of China for their kind assistance in this research. The authors also thank the students for their assistance in this research.

\section{Author details}

'Department of Sanitation Economy Administration, Nanfang Hospital, Southern Medical University, Guangzhou, Guangdong Province, PR China. ${ }^{2}$ School of Public Health and Tropical Medicine, Southern Medical University, Guangzhou, Guangdong Province, PR China. ${ }^{3}$ Medicare office, First People's Hospital, Shunde, Foshan, Guangdong Province, PR China. ${ }^{4}$ School of Nursing, Southern Medical University, Guangzhou, Guangdong Province, PR China.

\section{Authors' contributions}

JX developed the questionnaire and study design, supervised the analysis and contributed to the final version of the manuscript. JQ who assisted with 
the survey and data analyses is also the principal authors of this paper. JC, LZ, LF, YL, QW \& JZ assisted with the study. All authors have read and approved the final manuscript.

\section{Funding}

This research was supported by the Youth Project of Humanities and Social Sciences,Ministry of Education of China (NO: 10YJCZH192) and the Planned Science and Technology Project of Guangdong Province in China (NO: 2009B080701073).

Received: 18 November 2011 Accepted: 4 May 2012

Published: 4 May 2012

\section{References}

1. Word Health Organization: Report of the WHO meeting on the assessment of quality of life in health care. Geneva: WHO; 1991.

2. Word Health Organization: Report of meeting on quality of life. Geneva: WHO; 1992.

3. WHO: The development of the WHO quality of life assessment instrument Geneva: WHO; 1993.

4. Spitzer WO: State of science 1986: quality of life and functional status as target variables for research. J Chron Dis 1987, 40(6):465-471.

5. Hays D, Anderson R, Revicki D: Psychomtric considerations in evaluating health-related quality of life measures. Qual Life Res 1993, 2(6):441-449.

6. Yost KJ, Haan MN, Levine RA, Gold EB: Comparing SF-36 scores across three groups of women with different health profiles. Qual Life Res 2005, 14(5):1251-1261.

7. Izutsu T, Tsutsumi A, Matsuo Y, Yamada H, Kurita H, Wakai S: Validity and reliability of the Bangla version of WHOQOL-BREF on an adolescent population in Bangladesh. Qual Life Res 2005, 14(7):1783-1789.

8. Zebrack BJ, Chester MA: A psychometric analysis of the Quality of LifeCancer Survivors (QOL-CS) in survivors of childhood cancer. Qual Life Res 2001, 10(4):319-329.

9. Yildirim A, Akinci F, Gozu H, Sargin H, Orbay E, Sargin M: Translation, cultural adaptation, cross-validation of the Turkish diabetes quality-of-life (DQOL) measure. Qual Life Res 2007, 16(5):873-879.

10. Wu CH: Chinese civil servants'system. Tianjin: Nankai University Press; 2008:60-79.

11. Walters SJ: Sample size and power estimation for studies with health related quality of life outcomes: a comparison of four methods using the SF-36. Health Qual Life Outcomes 2004, 2:26-42.

12. Busse JW, Bhandari M, Guyatt GH, Heels-Ansdell D, Mandel S, Sanders D, Schemitsch E, Swiontkowski M, Tornetta P 3rd, Wai E, Walter SD, SPRINT Investigators: Use of both short musculoskeletal function assessment questionnaire and short form-36 among tibial-fracturepatients was redundant. Journal of Clinical Epidemiology 2009, 62(11):1210-7.

13. Mozes B, Maor $Y$, Shmueli A: The competing effects of disease states on quality of life of the elderly: the case of urinary symptoms in men. Qual Life Res 1999, 8(1-2):93-9.

14. Reulen RC, Zeegers MP, Jenkinson C, Lancashire ER, Winter DL, Jenney ME, Hawkins MM: The use of the SF-36 questionnaire in adult survivors of childhood cancer: evaluation of data quality, score reliability, and scaling assumptions. Health Qual Life Outcomes 2006, 4:77-84.

15. Pickard AS, Yang Y, Lee TA: Comparison of health-related quality of life measures in chronic obstructive pulmonary disease. Health Qual Life Outcomes 2011, 9:26-31.

16. Bentley TG, Palta M, Paulsen AJ, Cherepanov D, Dunham NC, Feeny D, Kaplan RM, Fryback DG: Race and gender associations between obesity and nine health-related quality-of-life measures. Qual Life Res 2011 20(5):665-674.

17. Xu J, Hu MY, Yang BY, Wang BH, Xie YN: The Medical Outcomes Study 36-Item Short-Form Health Survey. Chinese journal of behavioral medical science 1999, 8(2):150-152.

18. Lam CL, Tse EY, Gandek B, Fong DY: The SF-36 summary scales were valid, reliable, and equiv-alent in a Chinese population. J Clin Epidemiol 2005, 58(8):815-822

19. Ware JE Jr, Kosinski M, Bayliss MS, McHorney CA, Rogers WH, Raczek A: Comparison of methods for scoring and statistical analysis of SF-36 health profiles and summary measures: summary of results from the medical outcomes study. Med Care 1995, 33(Supp|4):AS264-279.
20. Perlstein TS, Lee RT: Smoking, metalloproteinase, and vascular disease. Arterioscler Thromb Vasc Biol 2006, 26(2):250-256.

21. Stranges S, Dorn JM, Shipley MJ, Kandala NB, Trevisan M, Miller MA, Donahue RP, Hovey KM, Ferrie JE, Marmot MG, Cappuccio FP: Correlates of short and long sleep duration: a cross-cultural comparison between the United Kingdom and the United States. American Journal of Epidemiology 2008, 168(12):1353-1364.

22. Su ZH, Hao W, Chen HX: Alcohol Patterns, Alcohol Consumption and Alcohol-Related Problems in Five Areas in China: Health Status of Drinkers Collaborate Group for 2nd Survey on Alcohol Drinking in Five Areas in China. Chinese Mental Health Journal 2003, 17(8):540-543.

23. Thun MJ: Alcohol consumption and mortality in middle-aged and elderly US adults. New England Journal of Medicine 1997, 337(24):1705-1714.

24. Doll R: Mortality in relation to consumption of alcohol:13 year's observations on male British doctors. British Medicine Journal 1994, 309(6959):9010-9018.

25. Bjartveit $K$, Tverdal A: Health consequences of smoking 1-4 cigarettes per day. Tob Control 2005, 14(5):315-320.

26. Taylor R, Najafi F, Dobson A: Meta-analysis of studies of passive smoking and lung cancer: effects of study type and Continent. Int J Epidemiol 2007, 36(8):1048-1059.

27. Schünemann HJ, Sperati F, Barba M, Santesso N, Melegari C, Akl EA, Guyatt $G$, Muti P: An instrument to assess quality of life in relation to nutrition: item generation, item reduction and initial validation. Health Qual Life Outcomes 2010, 8:26-38.

28. Kyle SD, Morgan K, Espie CA: Insomnia and health-related quality of life. Sleep Medicine Reviews 2010, 14(1):69-82.

29. Batty GD: Physical activity and coronary heart disease in older adults.A systematic review of epidemiological studies. Eur J Public Health 2002, 12(3):171-176

30. Batty GD, Lee IM: Physical activity for preventing strokes. BMJ 2002, 325(7360):350-351.

31. Jeon CY, Lokken RP, Hu FB, van Dam RM: Physical activity of moderate intensity and risk of type 2 diabetes: a systematic review. Diabetes Care 2007, 30(3):744-752.

32. Larson EB, Wang L, Bowen JD, McCormick WC, Teri L, Crane P, Kukull W: Exercise is associated with reduced risk for incident dementia among persons 65 years of age and older. Ann Intern Med 2006, 144(2):73-81.

33. Physical Activity Guidelines Advisory Committee Report, 2008. To the Secretary of Health and Human Services. Part A: executive summary. Nutr Rev 2009, 67(2):114-20

34. Virtanen M, Ferrie JE, Singh-Manoux A, Shipley MJ, Stansfeld SA, Marmot MG, Ahola K, Vahtera J, Kivimäki M: Long working hours and symptoms of anxiety and depression: a 5-year follow-up of the Whitehall II study. Psychol Med 2011, 18:1-10.

35. Sekine M, Chandol T, Martikainen P, Marmot M, Kagamimori S: Socioeconomic inequalities in physical and mental functioning of British, Finnish, and Japanese civil servants: Role of job demand, control, and work hours. Social Science \& Medicine 2009, 69(10):1417-1425.

36. Sato $Y$, Miyake $H$, Thériault G: Overtime work and stress response in a group of Japanese workers. Occup Med (Lond) 2009, 59(1):14-19.

37. Balboa-Castillo T, León-Muñoz LM, Graciani A, Rodríguez-Artalejo F, Guallar-Castillón P: Longitudinal association of physical activity and sedentary behavior during leisure time with health-related quality of life incommunity-dwelling older adults. Health Qual Life Outcomes 2011, 9:47-56.

doi:10.1186/1471-2458-12-330

Cite this article as: Xu et al:: Lifestyle and health-related quality of life: A cross-sectional study among civil servants in China. BMC Public Health 2012 12:330. 